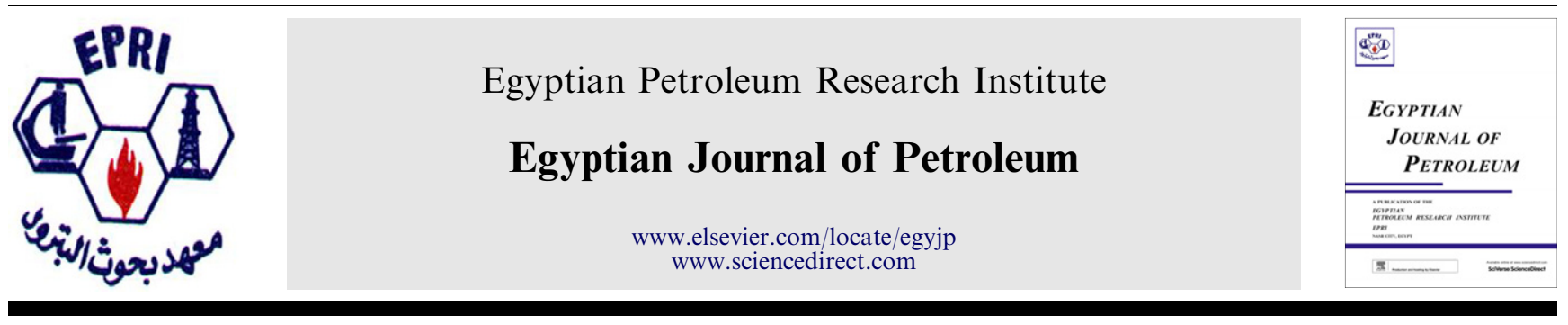

FULL LENGTH ARTICLE

\title{
Application of sustainable foaming agents to control the mobility of carbon dioxide in enhanced oil recovery
}

\author{
Roozbeh Rafati *, Hossein Hamidi, Ahmad Kamal Idris, Muhammad A. Manan
}

Faculty of Petroleum \& Renewable Energy Engineering (FPREE), Universiti Teknologi Malaysia (UTM), 81310 Skudai, Johor, Malaysia

Received 30 April 2012; Accepted 19 June 2012

Available online 23 January 2013

\section{KEYWORDS \\ Enhanced oil recovery; Foam flooding; Sustainable surfactant; Lignosulfonate; Alkyl Polyglucoside; Mobility control}

\begin{abstract}
Carbon dioxide $\left(\mathrm{CO}_{2}\right)$ flooding is a conventional process in which the $\mathrm{CO}_{2}$ is injected into the oil reservoir to increase the quantity of extracting oil. This process also controls the amount of released $\mathrm{CO}_{2}$ as a greenhouse gas in the atmosphere which is known as $\mathrm{CO}_{2}$ sequestration process. However, the mobility of the $\mathrm{CO}_{2}$ inside the hydrocarbon reservoir is higher than the crude oil and always viscous fingering and gravity override problems occur during a $\mathrm{CO}_{2}$ injection. The most common method to overcome these problems is to trap the gas bubbles in the liquid phase in the form of aqueous foam prior to $\mathrm{CO}_{2}$ injection. Although, the aqueous foams are not thermodynamically stable, special care should be considered to ensure bulk foam preparation and stability. Selection of a proper foaming agent from a large number of available surfactants is the main step in the bulk foam preparation. To meet this purpose, many chemical and crude oil based surfactants have been reported but most of them are not sustainable and have disposal problems. The objective of this experimental study is to employ Lignosulfonate and Alkyl Polyglucosides (APGs) as two sustainable foaming agents for the bulk foam stability investigations and foam flooding performance in porous media. In the initial part, the bulk foam stability results showed that APGs provided more stable foams in comparison with Lignosulfonate in all surfactant concentrations. In the second part, the results indicated that the bulk foam stability measurements provide a good indication of foam mobility in porous media. The foaming agent's concentration which provided the maximum foam stability also gave the highest value of mobility reduction in porous media.
\end{abstract}

(C) 2012 Egyptian Petroleum Research Institute. Production and hosting by Elsevier B.V.

Open access under CC BY-NC-ND license.
* Corresponding author.

E-mail address: roozbeh.rafati@yahoo.com (R. Rafati).

Peer review under responsibility of Egyptian Petroleum Research Institute.

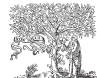

\section{Introduction}

Global warming is the rising average temperature of the Earth's atmosphere and oceans since the late 19th century and its projected continuation. Since the early 20th century, the Earth's average surface temperature has increased by about $0.8^{\circ} \mathrm{C}\left(1.4^{\circ} \mathrm{F}\right)$, with about two thirds of the increase occurring since $1980[1,2]$. Warming of the climate system is unequivocal, and scientists are more than $90 \%$ certain that 
most of it is caused by increasing concentrations of greenhouse gases produced by human activities such as deforestation and the burning of fossil fuels which makes carbon dioxide as a main product $[3,4]$. The greenhouse effect is the process by which absorption and emission of infrared radiation by gases in the atmosphere warm a planet's lower atmosphere and surface. It was proposed by Joseph Fourier in 1824 and was first investigated quantitatively by Svante Arrhenius in 1896 [5]. Naturally occurring amounts of greenhouse gases have a mean warming effect of about $33^{\circ} \mathrm{C}\left(59^{\circ} \mathrm{F}\right)$ [4]. The major greenhouse gases are water vapor, which causes about $36-70 \%$ of the greenhouse effect; carbon dioxide $\left(\mathrm{CO}_{2}\right)$, which causes 9 $26 \%$; methane $\left(\mathrm{CH}_{4}\right)$, which causes $4-9 \%$; and ozone $\left(\mathrm{O}_{3}\right)$, which causes 3-7\% [6]. Malaysia is one of the countries that produce a large amount of carbon dioxide as a green house gas in the World [7]. The amount of carbon dioxide production in Malaysia has a rough incremental trend which makes Malaysia the first place among the all neighboring countries as shown in the Fig. 1. It was 7.57 metric tons per capita that is much more than the World average about 4.5 metric tons per capita reported by the World Bank in 2012. Therefore, it is necessary to control the amount of $\mathrm{CO}_{2}$ as a greenhouse gas in Malaysia and also all over the World.

$\mathrm{CO}_{2}$ injection into hydrocarbon reservoir is reported by many scientists as one of the best methods for $\mathrm{CO}_{2}$ emission control and also enhanced oil recovery. $\mathrm{CO}_{2}$ for enhanced oil recovery has favorable characteristics such as dynamic miscibility achievement between $\mathrm{CO}_{2}$ and oil under most reservoir conditions, intermediate component extraction and heavy oil viscosity reduction which is named $\mathrm{CO}_{2}$ flooding process. However, $\mathrm{CO}_{2}$ flooding processes frequently experience viscous fingering and gravity override problems because of the low $\mathrm{CO}_{2}$ density and viscosity in comparison with the crude oil. As a result, sweep efficiency decreases and significant amounts of oil are left behind [8-11].

The need for mobility control during $\mathrm{CO}_{2}$ flooding has led to the study of foam processes, which involves the injection of $\mathrm{CO}_{2}$ together with an aqueous solution of a $\mathrm{CO}_{2}$-foaming agent [8]. $\mathrm{CO}_{2}$ has a very low viscosity in comparison to oil and water. However, when $\mathrm{CO}_{2}$ is a dispersed phase, as in foam, its apparent viscosity is greatly increased; thus, its mobility is improved [12]. From the time when the use of foam in reservoirs was first proposed in a patent by Bond and

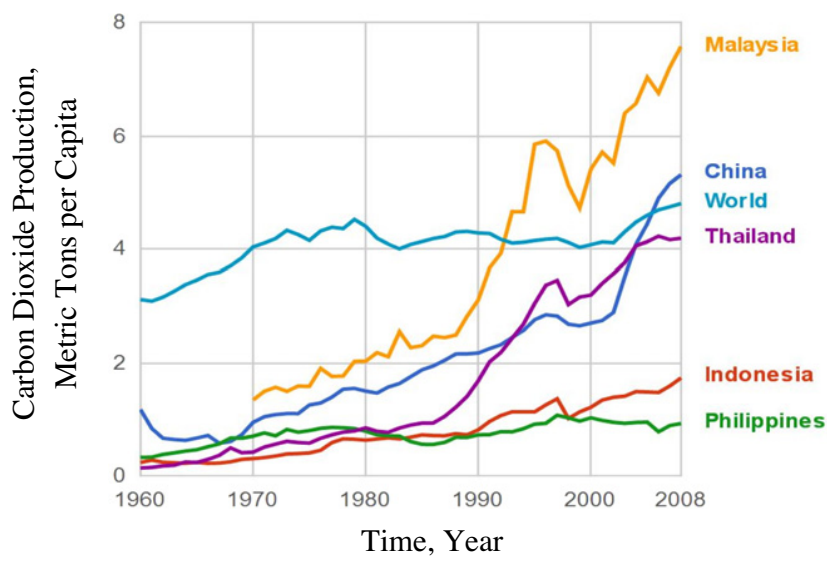

Figure 1 Carbon dioxide $\left(\mathrm{CO}_{2}\right)$ emissions per capita (World Bank 2012).
Holbrook (1958) which is reported by Bernard and Holm (1964) [13], it was usually implicitly assumed without specific mention, that foam would preferentially impede flow in the higher permeability layers or fractures in the reservoir that had already been swept of their oil. It was assumed without evidence that the unswept portions of the reservoir would remain at least as accessible and available to have their content displaced and forced into the production wells. Because of this assumption, many, if not most, of the reports of foam investigations included descriptions of core-floods with listings of oil recovered and ranked in the order of those values. This assumption for $\mathrm{CO}_{2}$ foam floods cannot be examined for validity without more thoroughly considering the processes involved in bulk foam stability. Also, it is necessary to examine the behavior in core samples.

One of the main parameters determines the success of foam flooding is the selection and concentration of proper foaming agents (surfactants). In two-phase colloidal systems such as bulk foam, a thin, intermediate region or boundary, known as the interface, lies between the dispersed and continuous phases. Interfacial properties are very important in foams because the gas bubbles have a large surface area, and even a modest surface energy per unit area can become a considerable total surface energy. If sufficient energy cannot be provided through mechanical energy input, then another alternative is to use surfactant chemistry to lower the interfacial free energy, or interfacial tension. According to this fact, the study of surfactant type and concentration is necessary for strong bulk foam generation. However, the chosen foaming agent should be sustainable, nontoxic and have less environmental disadvantages especially for the offshore field applications. Many screening studies to choose proper foaming agent have been performed by many scientists [14-26] but most of them used various petroleum based surfactants which potentially cause many ecological problems. In the recent years some reports are provided about sustainable surfactants that indicated that they are already used in the petroleum industry. They are applied in environmentally safe drilling fluids [27], in well cleaning agents [28], as foamers in heavy oil recovery [29] and for reducing interfacial tension in surfactant-induced tertiary oil recovery processes $[22,30]$. However, no attention has been given to the effect of these surfactants as a foaming agent on foam generation and stability to control the mobility of $\mathrm{CO}_{2}$ injection process. Therefore, the main aim of this paper is to evaluate two types of sustainable surfactants for $\mathrm{CO}_{2}$ mobility control applications in enhanced oil recovery.

\section{Experimental procedure}

Two sets of experiments are designed in this paper to achieve the research objectives. In the first set, a series of bulk foam stability tests have been performed using two sustainable foaming agents (surfactants) to understand the effect of surfactant types and concentration in the presence and absence of crude oil on bulk foam stability. In the second part, the core flooding tests are carried out to evaluate the influence of these two surfactants on incremental oil recovery, differential pressure and mobility reduction of gas injection process. The lists of the experimental runs are illustrated in the Tables 1 and 2 for bulk foam stability and core flooding studies, respectively. 
Table 1 Bulk foam stability experimental schedule.

\begin{tabular}{lllr}
\hline Number of runs & Surfactant type & Crude oil concentrations, ppm & Surfactant concentrations, ppm \\
\hline Run No.1 & Alkyl Polyglucoside (APGs) & No oil & 500 \\
Run No.2 & Alkyl Polyglucoside (APGs) & No oil & 1000 \\
Run No.3 & Alkyl Polyglucoside (APGs) & No oil & 5000 \\
Run No.4 & Alkyl Polyglucoside (APGs) & No oil & 10,000 \\
Run No.5 & Alkyl Polyglucoside (APGs) & 10,000 & 500 \\
Run No.6 & Alkyl Polyglucoside (APGs) & 10,000 & 1000 \\
Run No.7 & Alkyl Polyglucoside (APGs) & 10,000 & 5000 \\
Run No.8 & Alkyl Polyglucoside (APGs) & 10,000 & 10,000 \\
Run No.9 & Lignosulfonate & No oil & 500 \\
Run No.10 & Lignosulfonate & No oil & 1000 \\
Run No.11 & Lignosulfonate & No oil & 5000 \\
Run No.12 & Lignosulfonate & No oil & 10,000 \\
Run No.13 & Lignosulfonate & 10,000 & 500 \\
Run No.14 & Lignosulfonate & 10,000 & 1000 \\
Run No.15 & Lignosulfonate & 10,000 & 5000 \\
Run No.16 & Lignosulfonate & 10,000 & 10,000
\end{tabular}

Table 2 Core flooding experimental schedule.

\begin{tabular}{llllll}
\hline Number of runs & Name of the experiments & Gas flow rate, $\mathrm{ml} / \mathrm{min}$ & Liquid flow rate, ml/min & Foam quality & Capillary number \\
\hline Run No.1 & Gas injection & 9 & $\mathrm{~N} / \mathrm{A}$ & $\mathrm{N} / \mathrm{A}$ & $10^{-6}$ \\
Run No.2 & Lignosulfonate foam flooding & 9 & 4 & $86.2^{\%}$ & $10^{-5}$ \\
Run No.3 & APGs foam flooding & 9 & 4 & $64.7 \%$ & $10^{-5}$ \\
Run No.4 & Water flooding & N/A & 4 & N/A & $10^{-4}$ \\
Run No.5 & Lignosulfonate flooding & N/A & 4 & N/A & $10^{-4}$ \\
Run No.6 & APGs flooding & N/A & 4 & N/A & $10^{-4}$ \\
\hline
\end{tabular}

\subsection{Materials}

Lignosulfonate or sulfonated lignin and Alkyl Polyglucosides (APGs) surfactants are applied in the form of $60 \%$ active as two sustainable foaming agents for the bulk foam stability investigations. Lignosulfonate is recognized as an anionic surfactant which is a byproduct from the production of wood pulp using sulfite pulping and Alkyl Polyglucosides are known as nonionic surfactant which is regenerated from natural raw<smiles>[2H]Oc1cc(C(C(O)C(C)CCCCCCCCCC)S(=O)(=O)O)ccc1O</smiles>

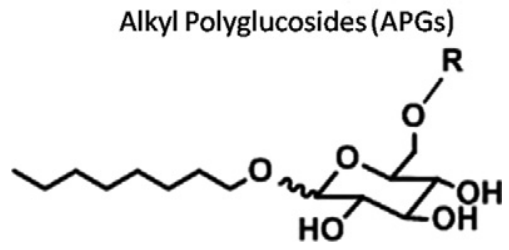

Figure 2 Chemical structure of Lignosite ${ }^{\circledR} 100$ and $\mathrm{C}_{8}$-APGs. materials such as glucose derived from corn and fatty alcohols from coconut and palm kernel oils (Fig. 2). The detailed properties of both surfactants are provided in a Table 3. Aqueous solutions of surfactants at a concentration from 500 to $10,000 \mathrm{ppm}$ in the range of above, below and equal to critical micelle concentration (CMC) were prepared to generate the foam in the presence and absence of swollen micelles. The synthetic type of mineral oil with the detailed properties in Table 4 is used to simulate the crude oil in both bulk foam stability and core flooding experiments. High purity $\mathrm{CO}_{2}$ is used in the ambient condition ( $14.7 \mathrm{psi}$ and $60^{\circ} \mathrm{F}$ ) for both series of experiments to simulate immiscible injection condition.

\subsection{Bulk foam stability experiments}

Foam stability test equipment is prepared and modified based on ASTM-D 6082-06, D892-06 and D1881-97 as indicated in Fig. 3. The equipment consisted of $560 \mathrm{cc}$ graduated transparent low pressure cylinder, $6 \mathrm{~cm}$ diameter and $60 \mathrm{~cm}$ length, spherical gas diffuser stone made of fused crystalline alumina grain, displacement pump and high purity carbon dioxide cylinder. The cell is first filled with the aqueous solution to be tested and the system was brought to the desired pressure by means of a positive displacement pump and temperature equilibrated in a thermostatic water bath. The pressure difference between the $\mathrm{CO}_{2}$ tank and the solution tank was determined and brought to zero. At this point $\mathrm{CO}_{2}$ was allowed to flow from the capillary tube into the bottom of the surfactant solution. The $\mathrm{CO}_{2}$ flowed upward through a gas diffuser at the lower end of the cell. Depending on the effectiveness of surfactants, the bubbles either formed a layer of foam-like dispersion 
Table 3 Sustainable surfactants properties.

\begin{tabular}{llllll}
\hline Trade name & Composition & Supplier & Hydrocarbon chain & Type & Appearance \\
\hline Lignosite ${ }^{\circledR} 100$ & Lignosulfonate & Georgia-Pacific & $\mathrm{C}_{20} \mathrm{H}_{26} \mathrm{O}_{10}$ & Anionic & Light brown \\
APGs & Alkyl Polyglucoside & Mistral Lab Chemicals & $\mathrm{C}_{16} \mathrm{H}_{32} \mathrm{O}_{6}$ & Nonionic & Light yellow \\
\hline
\end{tabular}

Table 4 Mineral oil properties.

\begin{tabular}{llllll}
\hline Trade Name & Supplier & Density $\mathrm{g} / \mathrm{mL}$ at $20{ }^{\circ} \mathrm{C}$ & Kinematic Viscosity, cS & CAS No. & Appearance \\
\hline Paraffin oil & QReC & 0.85 & 30 & $8012-95-1$ & Colorless \\
\hline
\end{tabular}

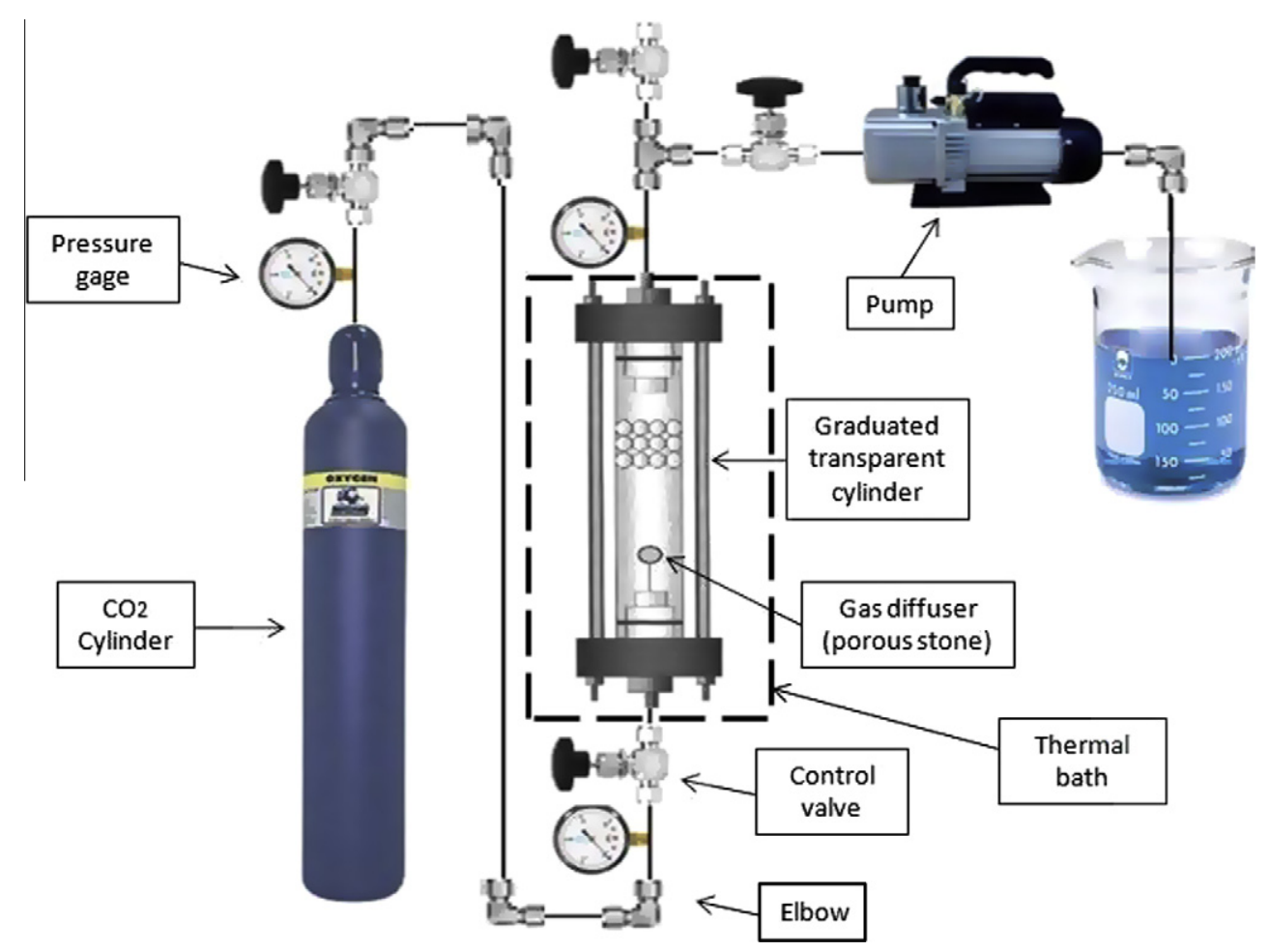

Figure 3 Bulk foam stability apparatus.

at the top of the transparent tube or coalesced into a clear layer of $\mathrm{CO}_{2}$ gas. After a standard volume of $\mathrm{CO}_{2}$ was introduced, the pump was stopped and the stability of foam determined by measuring the foam layer thickness versus time.

\subsection{Core flooding studies}

Unconsolidated sand pack with $32 \mathrm{~cm}$ length and $3 \mathrm{~cm}$ diameter was prepared to simulate the reservoir physical model as shown in Fig. 4. The packing material was the glass bead with the mesh size of 50-100 meshes. The porosity of the sand pack was $34 \%$ with the absolute permeability of $2180 \mathrm{md}$ (Table 5). The sand pack is located in the horizontal position to consider that the effect of gravity force is negligible. The rate of the liquid injection in core flooding experiments is maintained $4 \mathrm{ml} /$ min and for gas injection $9 \mathrm{ml} / \mathrm{min}$ to consider both gas and liquid injection are valid in the same range of capillary numbers. In the core flooding experiments, the reservoir model initially saturated with deionized water to simulate connate water saturation and to measure absolute permeability. The core next is flooded with oil to create initial oil saturation. This flood leaves a residual saturation of water comparable to that found as connate water in reservoirs. The sand pack is then flooded with gas, water, surfactant and foam to measure the amount of incremental oil recovery and volumetric sweep efficiency improvement. At the end of the experiment the results of $\mathrm{CO}_{2}$ injection are compared with water flooding, surfactant flooding and two sustainable $\mathrm{CO}_{2}$ foams.

\section{Experimental results}

The results of laboratory experiments for both bulk foam stability and foam flooding in porous media are analyzed and reported in this section.

\subsection{Bulk $\mathrm{CO}_{2}$ foam stability tests}

$\mathrm{CO}_{2}$ foam stability tests were conducted with Alkyl Polyglucosides (APGs) at different surfactant concentrations solubilized 


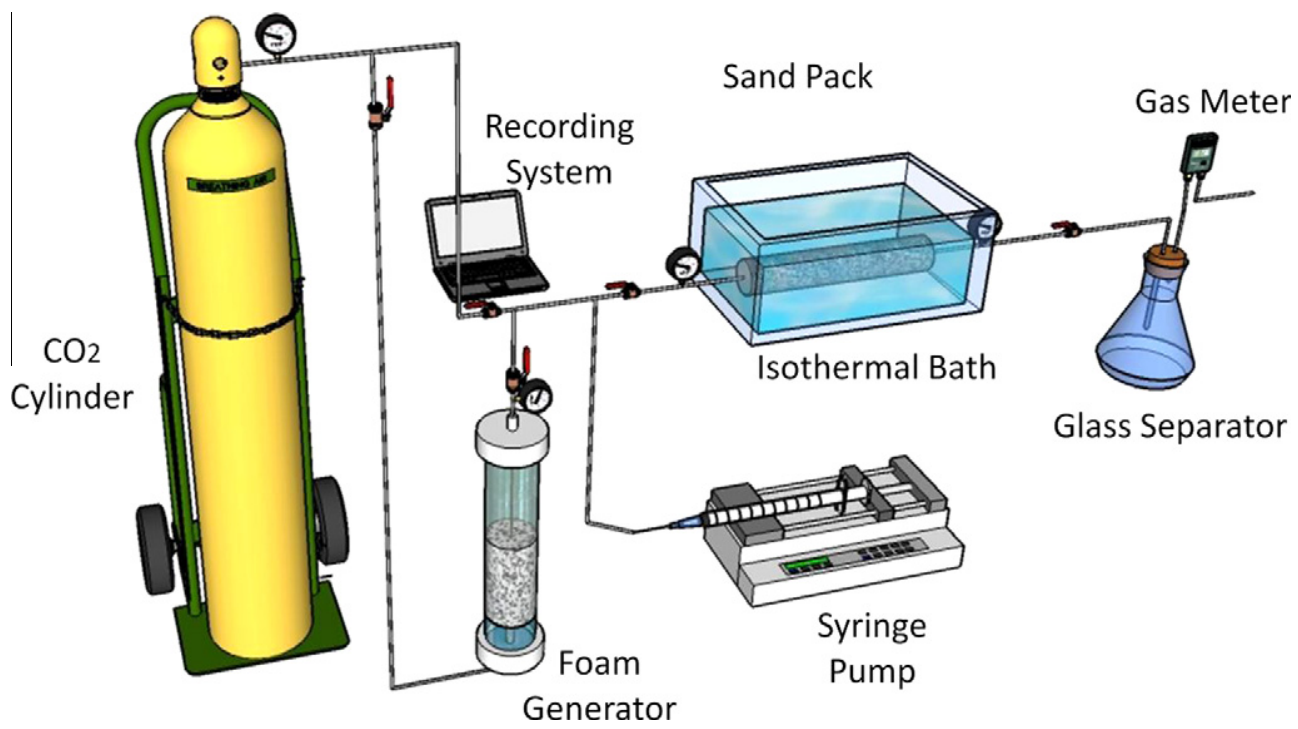

Figure 4 Core flooding apparatus.

Table 5 Sand pack properties.

\begin{tabular}{llllllllr}
\hline $\begin{array}{l}\text { Packing } \\
\text { materials }\end{array}$ & Mesh size & Length, cm & Diameter, $\mathrm{cm}$ & Porosity, \% & $\begin{array}{l}\text { Absolute } \\
\text { permeability, md }\end{array}$ & $\begin{array}{l}\text { Pore } \\
\text { volume, ml }\end{array}$ & OOIP, ml & Wettability \\
\hline Glass bead & $50-70$ & 32 & 3 & 0.34 & 2180 & 76.9 & 69 & Water wet \\
\hline
\end{tabular}

in the deionized water, $60{ }^{\circ} \mathrm{F}$, and $14.7 \mathrm{psi}$. The surfactant concentrations are 500, 1000, 5000 and $10,000 \mathrm{ppm}$, respectively. In the foam stability experiments, coalescence of bubbles was observed at all concentration versus time. Fig. 5 indicated that the foam collapse of Alkyl Polyglucosides (APGs) is a strong function of surfactant concentration. The results indicated that APGs with concentrations of 1000,5000 and $10,000 \mathrm{ppm}$ which are equal and more than the CMC are an excellent foaming agent. However, below CMC with 500 ppm concentration, foam stability test indicated very unstable APG foams. The volume reduction occurs because the liquid drains through the lamellae due to the force of gravity after foam generation

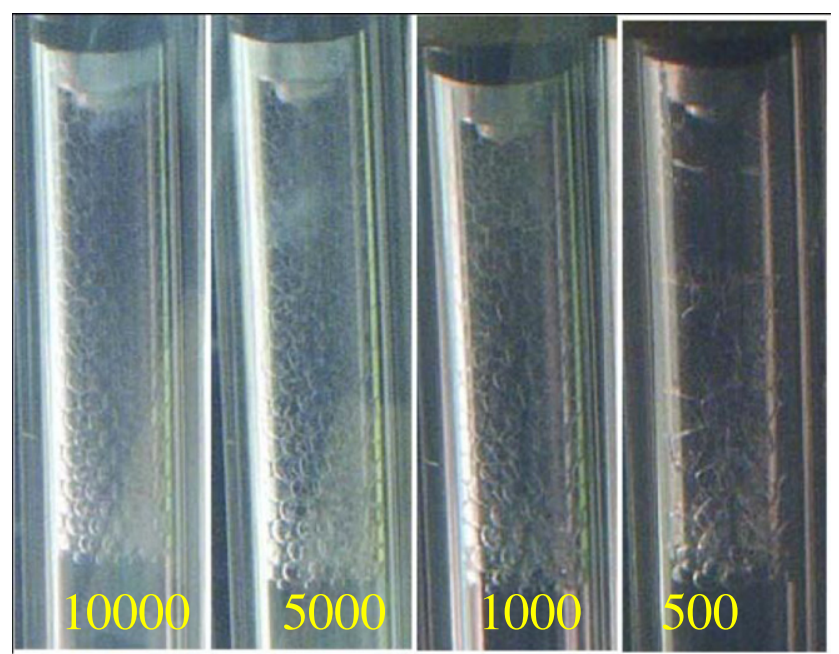

Figure 5 Foam stability of Alkyl Polyglucoside in various concentrations (ppm). and also surface elasticity reduction due to lack of enough surfactant concentration in the foam lamellas and plateau borders. As the lamellar fluid drains, the amount of surfactant in the lamella and plateau border decreases which causes lower surface viscosity and elasticity in the foam structure. The phenomena change the foam appearance by deforming the shape of the bubbles from spherical to polyhedral. In the tests, it is also being noticed that the lamellae in the upper layer of the foam are thinner than those in the lower layer of the foam due to gravity drainage. Draining continued until capillary forces were going to be equal to gravity forces and the gas-liquid interface curvature increases at the plateau borders. The increased curvature generates a low-pressure region in the plateau border area which caused higher pressure resides at flat thin-film region (lamellas). This pressure difference forces the liquid to flow toward the plateau borders and cause thinning of the films and motion in the foam. Fig. 6 indicated the foam height of different concentrations of Alkyl Polyglucosides (APGs) versus time. The results indicated that using $500 \mathrm{ppm}$ of Alkyl Polyglucosides (APGs) surfactant solution, the height of the foam generated after $25 \mathrm{~s}$ was $43.5 \mathrm{~cm}$. The overall time for this foam collapse was $23 \mathrm{~min}$. The foam stands for a much longer time to drain due to increase in surfactant concentration and governing the foam stability below the CMC by increasing interfacial rheological properties of the foam film. The results for $1000 \mathrm{ppm}$ of Alkyl Polyglucosides (APGs) surfactant solution indicated that the initial height of the foam generated in $25 \mathrm{~s}$ was $48.0 \mathrm{~cm}$ which is higher than the $500 \mathrm{ppm}$ concentration. This concentration of surfactant generates foam to stand as long as $75 \mathrm{~min}$ to drain. As shown in Fig. 6, the foam stands for a longer time to drain in comparison with $500 \mathrm{ppm}$. In the case of $5000 \mathrm{ppm}$ of Alkyl Polyglucosides (APGs) surfactant solution, the height of the foam 


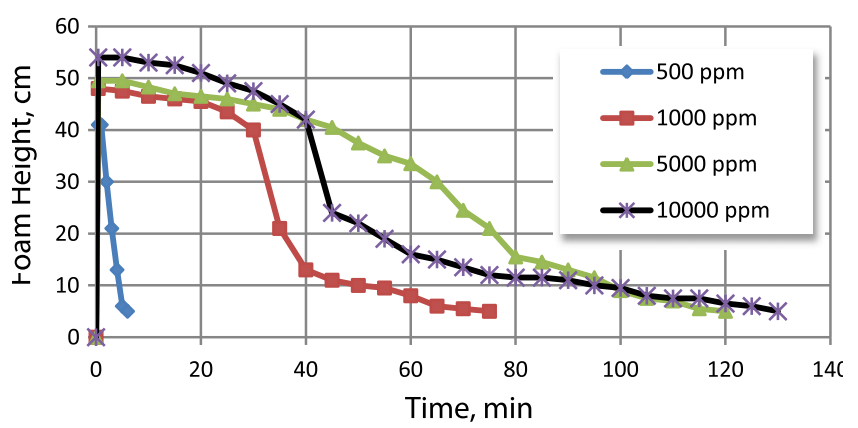

Figure 6 Foam stability of APGs at various surfactant concentrations.

generated after $25 \mathrm{~s}$ was recorded $49.5 \mathrm{~cm}$. The overall time for this foam to drain was $120 \mathrm{~min}$. The foam stands for a much longer time to drain due to the stability of the lamellae from this solution above CMC. The final concentration of Alkyl Polyglucosides (APGs) surfactant was 10,000 ppm much more above the critical micelle concentration. In this situation, the foam stability is governed by micelle concentration, structure and layering. The height of the foam generated after $25 \mathrm{~s}$ was $54 \mathrm{~cm}$. As shown in Fig. 6, the time recorded for the foam with $10,000 \mathrm{ppm}$ concentration to coalescence was $130 \mathrm{~min}$.

In the second part of the foam stability tests, the foamability and stability of lignosulfonate were examined in the same concentration as Alkyl Polyglucosides (APGs). Fig. 7 represents the result of static decay of $\mathrm{CO}_{2}$ foam using lignosulfonate solution as a foaming agent with deionized water. The amount of foam in this graph indicates the persistence of foam remaining inside the transparent cell after a standard volume of $\mathrm{CO}_{2}$ has been injected. The heights of foam generated from these solutions are very small, less than $20 \mathrm{~cm}$. This indicates that this solution is a weak foaming agent. The bubbles formed at $0.5 \mathrm{wt} . \%$ concentration of lignosulfonate coalesced in less than a minute. At higher concentrations, the percentage of foam increased and the bubbles lasted more than five minutes, but less than ten. The picture of the foam prepared using minimum to maximum amount of lignosulfonate concentration is provided in Fig. 8.

\subsection{Core flooding studies}

After the bulk foam stability tests, all concentrations of both surfactants are tested as a foaming agent in the core flooding

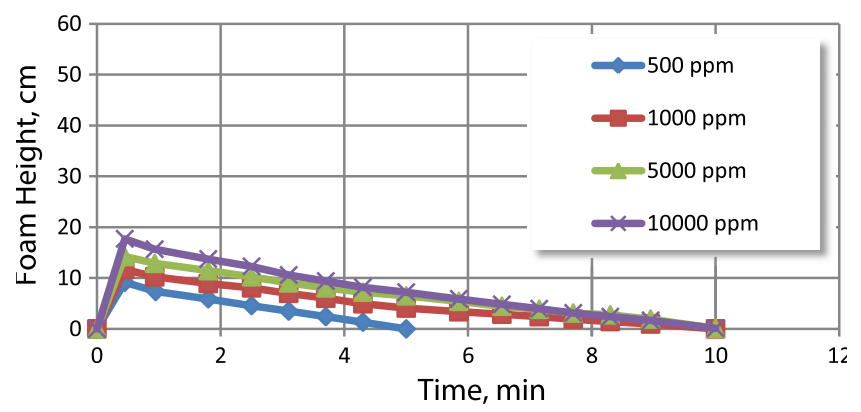

Figure 7 Foam stability of lignosulfonate at various surfactant concentrations.

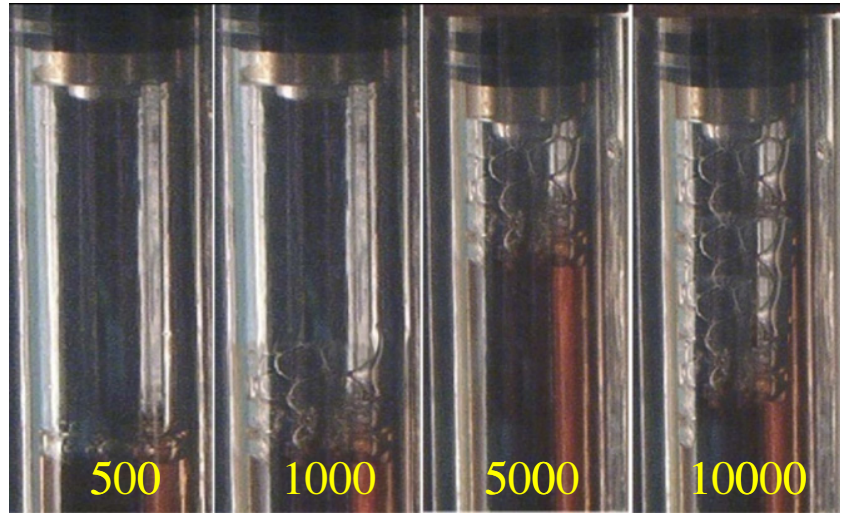

Figure 8 Foam stability of lignosulfonate at various concentrations (ppm).

experiments and the results are compared to the $\mathrm{CO}_{2}$ injection. The data for extra oil recovery and pressure drop are provided in this section. In the first part of the experiments $\mathrm{CO}_{2}$ alone was used as a displacing agent in the sand pack, breakthrough occurred after $0.26 \mathrm{PV}$ of fluid was injected. Co-injection of $\mathrm{CO}_{2}$ with Alkyl Alkyl Polyglucosides (APGs) solution at $500 \mathrm{ppm}$ simulated short cycles of foam flooding process. Delayed $\mathrm{CO}_{2}$ breakthrough was observed at $0.42 \mathrm{PV}$ for this run. When Alkyl Polyglucosides (APGs) at 1000 ppm were coinjected with $\mathrm{CO}_{2}$; the foam appeared to produce more oil and the breakthrough occurred after 0.48 PV of fluid was injected. When Alkyl Polyglucosides (APGs) at 5000 ppm were coinjected with $\mathrm{CO}_{2}$, carbon dioxide breakthrough occurred at 0.65 $\mathrm{PV}$ and the foam flooding performance was improved. In the 1000 ppm of Alkyl Polyglucosides (APGs) as a foaming agent, the gas breakthrough occurred at $0.7 \mathrm{PV}$ which confirms more improvements in the gas oil ratio by surfactant concentration. Fig. 9 indicated the results of plotting the cumulative gas oil ratio (GOR) as a function of total pore volume injected. The highest cumulative GOR occurred when $\mathrm{CO}_{2}$ only was used as the displacing agent. Coinjected $\mathrm{CO}_{2}$ with foam reduced the cumulative GOR when surfactant at 500, 1000, 5000 and $10,000 \mathrm{ppm}$ in form of $\mathrm{CO}_{2}$ foam was injected to the sand pack, the amount of GOR substantially reduced.

The oil recovery from the sand pack is also recorded for various injected fluids as a function of total pore volumes of displacing fluid injected. Each test is repeated for three times to check the repeatability of the experiments. The gas injection is used as a base case of the experiments to determine the amount of oil recovery as a function of pore volume injected. The oil recovery versus pore volume injected for the base case experiment is indicated in Fig. 10. The results indicated that the gas injection can only recover $27.3 \%$ of original oil in place. After the gas injection process the foam is introduced into the system to decrease the mobility of gas injection in the sand pack. The results indicated that during each test, 8 $\mathrm{PV}$ of fluid was injected, about $56 \%$ of the oil was produced by a maximum concentration of Alkyl Polyglucosides (APGs). The results of tests during injection of carbon dioxide as a gas were compared with lignosulfonate and Alkyl Polyglucosides (APGs). The oil production was observed higher for the system of Alkyl Polyglucosides (APGs). Fig. 11 also compared the results of oil production of Alkyl Polyglucosides (APGs) and lignosulfonate both at $10,000 \mathrm{ppm}$ (highest bulk foam 


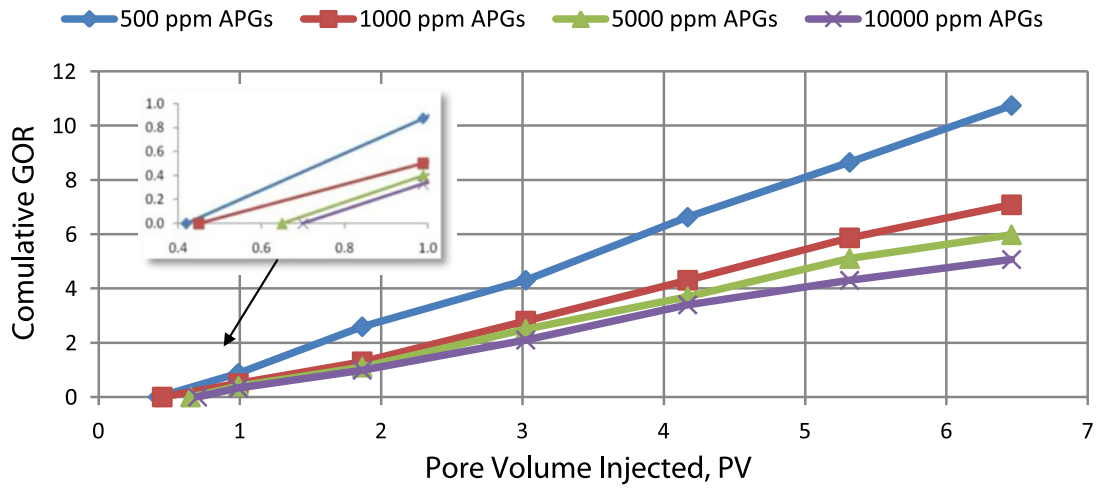

Figure 9 Gas oil ratio (GOR) as a function of pore volume injected.

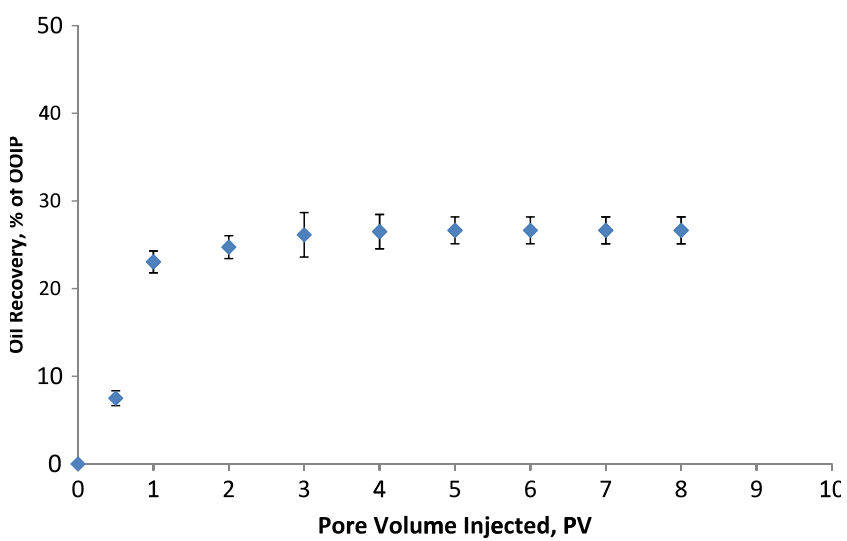

Figure 10 Oil recovery in the single gas injection process.

stability) that indicated the oil production of Alkyl Polyglucosides (APGs) that produced about 56 percent of original oil in place in comparison with $33.3 \%$ oil production of lignosulfonate as a foaming agent. The sweep efficiency of lignosulfonate was not very effective, because the foam was not as strong as Alkyl Polyglucosides (APGs). Therefore, the lignosulfonate is not recognized as a strong foaming agent in comparison with Alkyl Polyglucosides (APGs) and oil based surfactants. Pressure drop profiles for Alkyl Polyglucosides (APGs) and lignosulfonate are provided in Fig. 12. The pressure drop of Alkyl Polyglucosides (APGs) at 10,000 ppm was much higher than lignosulfonate at $10,000 \mathrm{ppm}$ which is because of more stable foams provided by Alkyl Polyglucosides (APGs). At the end of the foam experiments water and surfactant flooding was introduced into the system to compare their results with the foam flooding process. From the results it can be understood that the quantity of the oil recovery by APGs foams is between gas and water flooding processes.

\section{Feasibility study}

Simplified economics can be estimated with the data gathered for the prices of the conventional oil based surfactants which are compared with the sustainable surfactants proposed in this paper. This is a key point because however technically proven it may be, the process will never be trusted by operators unless incremental barrels of oil can be produced economically. The economical evaluation is performed based on $105 \mathrm{USD} / \mathrm{bbl}$ of the crude oil which is the average of OPEC oil price in the years 2011 and 2012. Also, the price of the surfactant systems is evaluated at critical micelle concentration based on the industrial scale preparation. As shown in Fig. 13, the overall cost of oil production using conventional (petroleum based) type of surfactant is between 20 and $30 \mathrm{USD} / \mathrm{bbl}$ which is much higher than the sustainable surfactants about 10 $15 \mathrm{USD} / \mathrm{bbl}$. The reason of the price difference is that most of the conventional surfactants are petroleum price dependent and their price increases when the crude oil price rises in the World. However, they can be produced easily in the largest

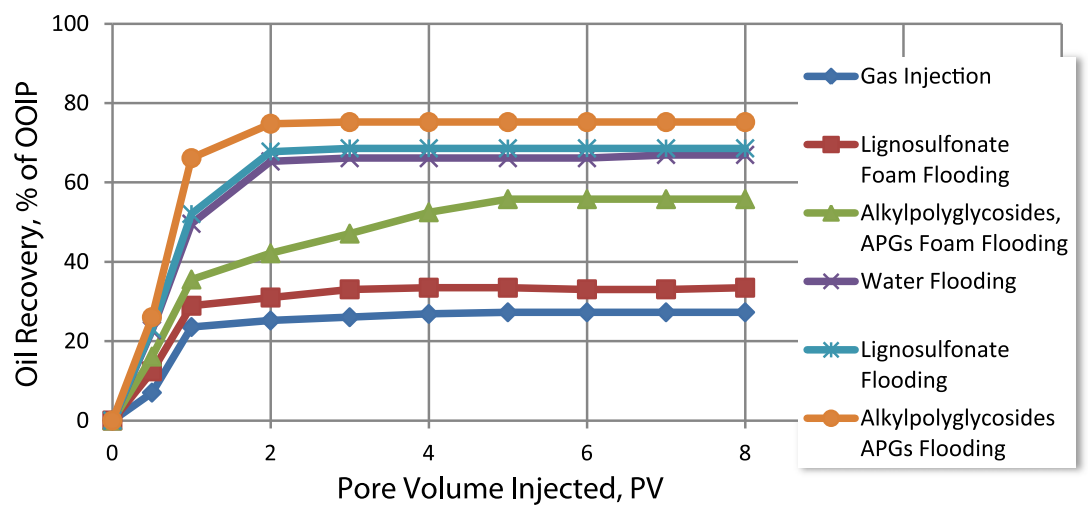

Figure 11 Oil recovery of various injection systems (10,000 ppm of both surfactants). 


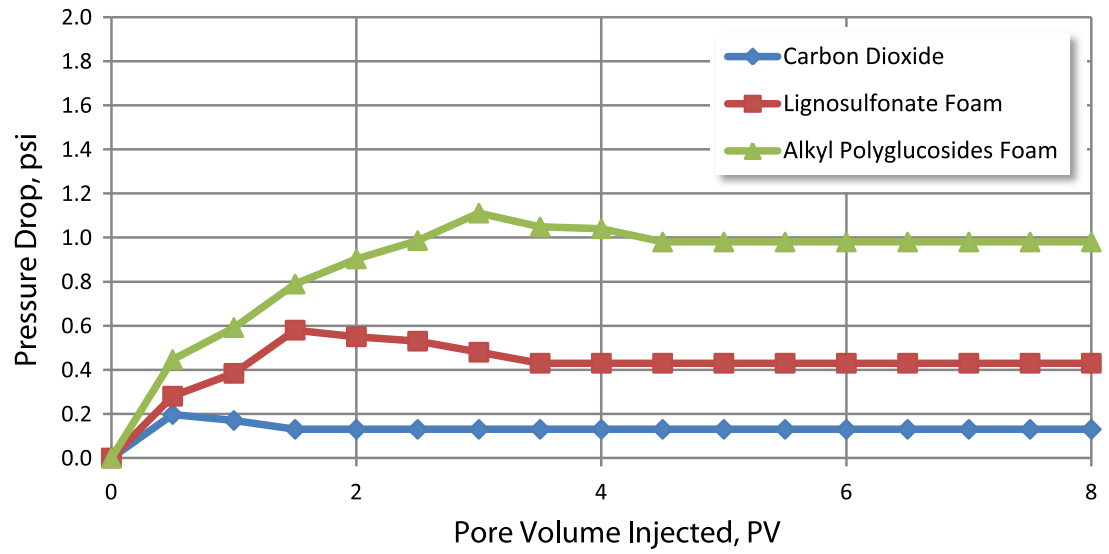

Figure 12 Pressure drop as a function of PV injected (10,000 ppm of both surfactants).

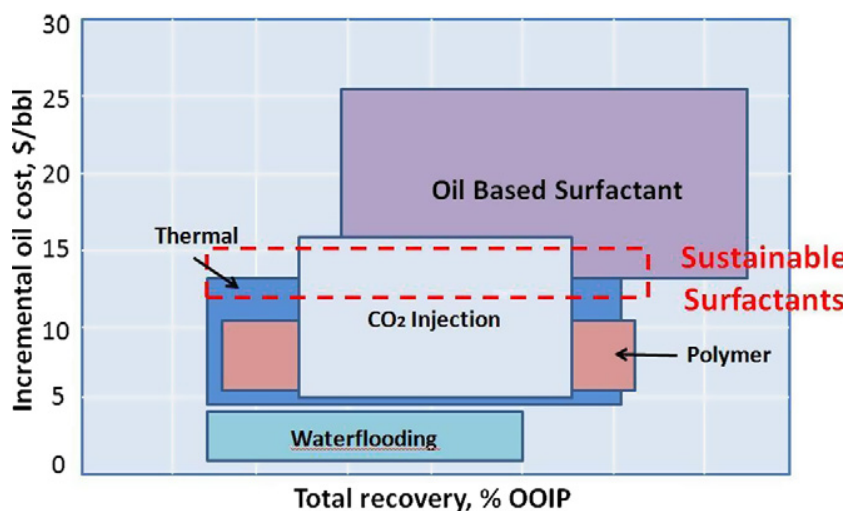

Figure 13 Economical evaluation of using sustainable surfactants.

scale in comparison with the sustainable surfactants. In the case of surfactant application as a foaming agent, the surfactant amount required is only $20-30 \%$ of the surfactant which is normally used for the single surfactant flooding. Based on the economical evaluation, it can be concluded that the foam flooding using sustainable surfactants is one of the most economical methods among all other surfactant applications in enhanced oil recovery (see Fig. 13).

\section{Conclusions}

1. Bulk Foam stability of both lignosulfonate and Alkyl Polyglucosides (APGs) is enhanced by increasing the surfactant concentration.

2. Alkyl Polyglucosides (APGs) are found as good foaming agent that remained about $130 \mathrm{~min}$ at maximum $(10,000 \mathrm{ppm})$ surfactant concentration.

3. Alkyl Polyglucosides (APGs) are recognized as a stronger foaming agent that prepared $54 \mathrm{~cm}$ initial foam height in comparison with lignosulfonate which only made about $20 \mathrm{~cm}$.

4. Gas Oil ratio (GOR) is decreased during a core flooding studies of Alkyl Polyglucosides (APGs) as the surfactant concentration increased.

5. The quantity of oil recovery increased using both foaming system in comparison with carbon dioxide solely.
6. The results of Alkyl Polyglucosides (APGs) recovery at $10,000 \mathrm{ppm}$ concentration (highest bulk foam stability) indicated $56 \%$ of OOIP which is higher in comparison with only $33.3 \%$ oil recovery of lignosulfonate as a foaming agent.

\section{Acknowledgment}

The authors wish to express their appreciation to the Universiti Teknologi Malaysia for providing adequate research facilities and relevant databases.

\section{References}

[1] A. Voiland, H. Riebeek, 2009 Ends warmest decade on record. NASA Earth, Observatory, 22 January 2010, 2010.

[2] A. Carnesale, W. Chameides, America's Climate Choices, The National Academies Press, 2011.

[3] P.A. Matson, T. Dietz, W. Abdalati, A.J. Busalacchi, K. Caldeira, R.W. Corell, R.S. Defries, I.Y. Fung, S. Gaines, G.M. Hornberger, M.C. Lemos, S.C. Moser, R.H. Moss, E.A. Parson, A. Ravishankara, R.W. Schmitt, L. Turner, W.M. Washington, J.P. Weyant, D.A. Whelan, Advancing the Science of Climate Change, The National Academies Press, Washington, D.C., 2010.

[4] R.K. Pachauri, A. Reisinger, Climate change 2007: synthesis report, Intergovernmental Panel on Climate Change (IPCC), Switzerland, 2007.

[5] S.R. Weart, The Carbon Dioxide Greenhouse Effect, American Institute of Physics, 2008.

[6] J.T. Kiehl, K.E. Trenberth, Bull. Am. Meteorol. Soc. 78 (1997) 197-208.

[7] World-Bank, World Bank Geopolitical Data Series [Online]. Available from: <http://data.worldbank.org/ $>$.

[8] S.-H. Chang, R.B. Grigg, Effects of foam quality and flow rate on $\mathrm{CO}_{2}$-foam behavior at reservoir temperature and pressure, SPE Reservoir Evaluation \& Engineering, 01/01/1999 1999, SPE 56856.

[9] O.G. Apaydin, A.R. Kovscek, Transp. Porous Media 43 (2001) 511-536.

[10] V.Q. Le, Q.P. Nguyen, A. Sanders, A novel foam concept with $\mathrm{CO}_{2}$ dissolved surfactants, in: Presented at the SPE/DOE Symposium on Improved Oil Recovery, Tulsa, Oklahoma, USA, 2008, SPE 113370.

[11] H. Panahi, Improving the recovery factor of heavy crude reservoirs by co-injecting $\mathrm{CO}_{2}$ and other conventional gaseous 
injecting materials at immiscibility condition with foam, in: Presented at the SPE International Petroleum Conference in Mexico, Puebla Pue, Mexico, 2004, SPE 92011.

[12] Y. Liu, R.B. Grigg, R.K. Svec, Foam mobility and adsorption in carbonate core, in: Presented at the SPE/DOE Symposium on Improved Oil Recovery, Tulsa, Oklahoma, USA, 2006, SPE 99756.

[13] G.G. Bernard, L.W. Holm, Effect of Foam on Permeability of Porous Media to Gas, vol. 4, 1964, SPE 983.

[14] J.P. Heller, C.L. Lien, M.S. Kuntamukkula, Foamlike Dispersions for Mobility Control in $\mathrm{CO}_{2}$ Floods, 01/01/1985, 1985, SPE 11233.

[15] R.J. Keeling, $\mathrm{CO}_{2}$ Miscible flooding evaluation of the south welch unit, welch san andres field, in: Presented at the SPE Enhanced Oil Recovery Symposium, Tulsa, Oklahoma, 1984, SPE 12664

[16] B.B. Maini, V. Ma, Relationship between foam stability measured in static tests and flow behavior of foams in porous media, in: Presented at the SPE Annual Technical Conference and Exhibition, Houston, Texas, 1984, SPE 13073.

[17] J.K. Borchardt, D.B. Bright, M.K. Dickson, S.L. Wellington, Surfactants for $\mathrm{CO}_{2}$ foam flooding, in: Presented at the SPE Annual Technical Conference and Exhibition, Las Vegas, Nevada, 1985, 14394.

[18] F.E. Suffridge, K.T. Raterman, G.C. Russell, Foam performance under reservoir conditions, in: Presented at the SPE Annual Technical Conference and Exhibition, San Antonio, Texas, 1989, SPE 19691.

[19] J.E. Hanssen, M. Dalland, Foams for effective gas blockage in the presence of crude oil, in: Presented at the SPE/DOE Enhanced Oil Recovery Symposium, Tulsa, Oklahoma, 1990, SPE 20193.

[20] J.K. Borchardt, A.R. Strycker, Olefin sulfonates for high temperature steam mobility control: structure-property correlations, in: Presented at the International Symposium on Oilfield Chemistry, Houston, Texas, 1997, SPE 37219.

[21] K. Mannhardt, J.J. Novosad, L.L. Schramm, Foam/oil interations at reservoir conditions, in: Presented at the SPE/ DOE Improved Oil Recovery Symposium, Tulsa, Oklahoma, 1998, SPE 39681.
[22] A.E. Syahputra, J.-S. Tsau, R.B. Grigg, Laboratory evaluation of using lignosulfonate and surfactant mixture in $\mathrm{CO}_{2}$ flooding, in: Presented at the SPE/DOE Improved Oil Recovery Symposium, Tulsa, Oklahoma, 2000, SPE 59368.

[23] Y. Rojas, S. Kakadjian, A. Aponte, R. Marquez, G. Sanchez, Stability and rheological behavior of aqueous foams for underbalanced drilling, In: Presented at the SPE International Symposium on Oilfield Chemistry, Houston, Texas, 2001, SPE 64999.

[24] W. Demin, C. Jiecheng, Y. Zhenyu, L. Qun, W. Wenxiang, Y. Huiyu, Successful field test of the first ultra-low interfacial tension foam flood, in: Presented at the SPE Asia Pacific Improved Oil Recovery Conference, Kuala Lumpur, Malaysia, 2001, SPE 72147.

[25] L. Marcano, X.S. Gutierrez, B. Perez, E. Martinez, Effect of some physical-chemical variables on the formation and stability of foam in oil-gas systems and their correlation with the formation of foaming crude oil, in: Presented at the Latin American and Caribbean Petroleum Engineering Conference, Cartagena de Indias, Colombia, 2009, SPE-123060-MS.

[26] A. Andrianov, R. Farajzadeh, M.M. Nick, M. Talanana, P.L.J. Zitha, Immiscible foam for enhancing oil recovery: bulk and porous media experiments, in: Presented at the SPE Enhanced Oil Recovery Conference, Kuala Lumpur, Malaysia, 2011, SPE 143578-MS.

[27] T.O. Walker, Environmentally Safe Drilling Fluid, 5403820, 1995.

[28] A. Forgiarini, L. Quintero, D. Jonesclark, A. Gabrysch, J.-L. Salager, Single phase microemulsions and in situ microemulsions for cleaning formation damage, USA Patent WO2009006251, 2008.

[29] A. Wael, F. Joao, S.G. Horvath, A. Peats, M. Samuel, Chemically enhanced thermal recovery of heavy oil, WO2009042284, 2009.

[30] M. Santa, G.A. Jalrgenson, S. Busch, P. Birnbrich, C. Spindler, G. Brodt, Sustainable surfactants in enhanced oil recovery, in: Presented at the SPE Enhanced Oil Recovery Conference, Kuala Lumpur, Malaysia, 2011, SPE 145039-MS. 